\title{
Practicing what we preach: A pilot study on oral health practices of dentists in Massachusetts
}

\author{
Romesh P. Nalliah ${ }^{1}$ (D) | Veerasathpurush Allareddy ${ }^{2}$
}

${ }^{1}$ Office of Patient Services, School of Dentistry, University of Michigan, Ann Arbor, MI, USA

${ }^{2}$ Department of Orthodontics, College of Dentistry, University of lowa, lowa City, IA, USA

Correspondence

Dr Romesh P. Nalliah, Office of Patient Services, School of Dentistry, University of Michigan, Ann Arbor, MI, USA.

Email: romeshn@umich.edu

\begin{abstract}
Aim: Dentists are perceived as leaders and role models of good oral health, but do dentists practice what they preach? The current study was a pilot evaluation dentists of the oral health and oral health practices of dentists in Massachusetts.

Methods: The Massachusetts Dental Society sent emails to 3957 member dentists for whom an email contact was available. One reminder was sent 3 months later, and there was no incentive offered. Institutional review board approval was acquired prior to administering the survey through the Harvard Medical School Committee on Human Studies.

Results: A total of $4.9 \%$ of dentists had a comprehensive oral examination more than 8 years ago, and $3.1 \%$ had diagnostic bitewings $3-5$ years ago. Our study revealed that $5.8 \%$ had untreated caries and only $70.8 \%$ reported having no oral health problems. A total of $37 \%$ reported that lack of time was a barrier in seeking care, and $7.8 \%$ reported financial barriers. Finally, $4.1 \%$ reported that a non-dentist coworker examined and managed their oral health.

Conclusions: The current study revealed that many dentists are not following American Dental Association guidelines for prevention for themselves. Subsequently, many in our profession are recommending preventive care for their patients that they are not adhering to themselves.
\end{abstract}

KEYWORDS

access, dentist, oral health, role model

\section{INTRODUCTION}

Members of the dental profession are considered to be role models for good oral health. Dentists, dental assistants, dental hygienists, and even front desk staff have an important role in advocating for oral health within their professional and social circles. Dentists are perceived as leaders and role models of good oral health, but do dentists practice what they preach? Do dentists brush twice per day, floss once per day, have 6-monthly check-ups, and cleanings? Additionally, do dentists have good general health practices in relation to medical evaluations?

Although dentistry aims to be an evidence-based profession, there are still major shortcomings in research data which prohibit evidence-based practice in many situations and require critical thinking. Moreover, a dentist's beliefs can influence their practice behaviors, and this has been demonstrated in the context of treating diabetic patients. ${ }^{1}$ Subsequently, variations in dentists' beliefs related to oral health could affect patient care, and the way dentists regard their own oral health might reflect their personal beliefs.

The objective of the current study was to evaluate the oral health practices of dentists in Massachusetts. To our knowledge, there has been no similar study surveying practicing dentists about their own oral health practices. The current paper was a follow up to a study of the general health and health practices of dentists, which was published in this journal in April $2017 .^{2}$ 


\section{2 | MATERIALS AND METHODS}

We developed the survey questions related to oral health, and the whole survey (including oral health questions) was validated by dentists from the Dental Health and Wellness Committee of the Massachusetts Dental Society (MDS). The surveys contained 36 questions relating to demographics, general health, and health practices. Institutional review board approval was acquired prior to administering the survey through the Harvard Medical School Committee on Human Studies (study no.: 23952). The current study focused on the oral health of dentists. More details of the overall survey is available from the original study on which the present study is based. ${ }^{2}$

The MDS sent emails to every member dentist who had provided their email address, and this summed to 3957 individuals. One reminder was sent 3 months later and there was no incentive offered. Simple descriptive statistics were utilized to demonstrate findings.

\section{3 | RESULTS}

Overall, 399 licensed dentists of the 3957 invited, who were members of the MDS, responded to the survey and completed all items, equating to a participation rate of $10.1 \%$.

Table 1 is adapted from the original paper. ${ }^{2}$ The demographic data from that study is represented in the left column, and the right column is taken from the current American Dental Association (ADA) data about its members. This shows that the demographic in the current study was somewhat similar to the overall demographic of ADA member dentists (which represents approximately $82 \%$ of US dentists). ${ }^{3,4}$ A total of $21.6 \%$ of respondents were female, $78.8 \%$ were general dentists, $50.4 \%$ worked in solo practice, and $32.6 \%$ were aged 56-65 years.

We found that $43.7 \%$ had a comprehensive dental examination $<6$ months ago, $23.5 \%$ had it $6-12$ months ago, $8.5 \%$ had it 18 36 months ago, and $4.9 \%$ had it $>8$ years ago. We also found that $29.2 \%$ had diagnostic bitewings $<6$ months ago, $37.7 \%$ had them 6-12 months ago, $16.9 \%$ had them $12-18$ months ago, $11.8 \%$ had them 18-36 months ago, and 3.1\% had them 3-5 years ago. Interestingly, $29.4 \%$ reported that a co-worker dentist checked and managed their oral health, while $4.1 \%$ reported that a co-worker non-dentist checked and managed their oral health.

Our study revealed that $5.8 \%$ of dentists in Massachusetts have untreated dental caries, $14.8 \%$ have fractured restorations, $0.3 \%$ had toothache, $3.3 \%$ had teeth requiring extraction, and only $70.8 \%$ reported having no oral health problems. We found that $11.1 \%$ of dentists in Massachusetts brush $>3$ times per day, 28.3\% brush 3 times daily, 51.2\% brush 2 times daily, $8.7 \%$ brush once daily, and $0.8 \%$ brush less frequently than daily. We also found that only $52.6 \%$ of dentists in Massachusetts floss daily, $17.7 \%$ brush once every few days, $6.4 \%$ floss once per week, and $2.8 \%$ never floss.

When considering obstacles that dentists face in trying to access medical and dental care, $37 \%$ reported a lack of time, $7.8 \%$ reported
TABLE 1 Demographics of survey responders compared to ADA membership

\begin{tabular}{|c|c|}
\hline $\begin{array}{l}\text { Characteristics of respondents to } \\
\text { our survey in Massachusetts }{ }^{2}\end{array}$ & $\begin{array}{l}\text { Characteristics of ADA dentists } \\
\text { across the USA }\end{array}$ \\
\hline $21.6 \%$ were female dentists & $\begin{array}{l}22.2 \% \text { of dentists in the USA } \\
\text { were female }\end{array}$ \\
\hline $78.8 \%$ were general dentists & $79.0 \%$ were general dentists ${ }^{3}$ \\
\hline $50.4 \%$ worked in solo practice & $59 \%$ worked in solo practice 6 \\
\hline $\begin{array}{l}1.8 \% \text { worked in large corporate } \\
\text { practice }\end{array}$ & $\begin{array}{l}5.0 \% \text { worked in large corporate } \\
\text { practice }^{7}\end{array}$ \\
\hline $\begin{array}{l}33.2 \% \text { worked in smaller group } \\
\text { practices }\end{array}$ & $\begin{array}{l}26.0 \% \text { worked in smaller group }^{\text {practices }^{7}}\end{array}$ \\
\hline $6.0 \%$ were $26-35$ years old & $11.1 \%<35$ years old ${ }^{7}$ \\
\hline $9.3 \%$ were $36-45$ years old & $19.2 \%$ were $35-44$ years old ${ }^{7}$ \\
\hline $21.6 \%$ were $46-55$ years old & $20.4 \%$ were $45-54$ years old ${ }^{7}$ \\
\hline $32.6 \%$ were $56-65$ years old & $28.5 \%$ were $55-64$ years old $^{7}$ \\
\hline $23.1 \%$ were $66-75$ years old & $20.8 \%$ were $>65^{7}$ \\
\hline $7.2 \%$ were $>75$ years old & \\
\hline
\end{tabular}

ADA, American Dental Association.

finances, $1.8 \%$ reported lack of skill of the physician/dentist nearby, and $1.5 \%$ reported geographic barriers with no physician/dentist nearby.

\section{4 | DISCUSSION}

The current pilot study describes findings from a survey of self-reported oral health and oral health practices of dentists in Massachusetts, and there is some comparability of our pilot survey data to the national figures in relation to the distribution of sex, specialty, practice setting, and age (Tables 1 and 2). Although the response rate was low (10.1\%) the survey tool, Survey Gizmo, reports that a response rate of $10 \%$ is acceptable for an external, online survey with no incentive. ${ }^{8}$ Additionally, the demographics of our survey respondents are comparable to dentists across the USA, which suggests that our pilot study has some value and limited generalizability.

The ADA recommends that patients brush twice per day ${ }^{9}$ and floss once per day. Remarkably, only $52.6 \%$ of dentists in our study flossed once per day (see Table 2); $2.8 \%$ reported never flossing and $6.4 \%$ reported flossing only once per week (Figure 1). In relation to brushing, only $90.5 \%$ of dentists brushed twice or more per day, even though the ADA advises patients to brush twice a day for 2 minutes each time. ${ }^{10}$ Our study also found that $8.7 \%$ of dentists only brush once per day. Surprisingly, $0.8 \%$ of dentists reported brushing less than once per day.

Colgate (New York, NY, USA) recommends dental examinations every 6 months; ${ }^{11}$ however, the ADA and Delta Dental websites describe how the dentist will make a customized recall plan based on the risk factors each patient has. ${ }^{12,13}$ As shown in Figure 2, we found that only $43.7 \%$ of dentists had a dental exam within the past 6 months. Moreover, only $67.2 \%$ of dentists reported having an exam within the past 12 months; this means that when $32.8 \%$ of dentists ask patients 
to have an examination every 12 months, we are asking them to do something we are not willing to do. It is of concern that $4.9 \%$ of dentists reported not having had a dental exam in the past 8 years.

In the current study, we found that $29.2 \%$ of dentists had their most recent bitewing radiographs within 6 months (Figure 2). In total, $95.6 \%$ had received bitewing radiographs within 3 years. ADA guidelines for bitewings note that a recall patient with no clinical caries and low caries risk should have radiographs every $18-36$ months. ${ }^{14}$ For recall patients with more than low caries risk, bitewings should be taken every $6-18$ months. ${ }^{14}$ Notably, we found that $4.4 \%$ of dentists in the current study had not had bitewings in at least 3 years.

An interesting finding in the current study was the presence of oral health conditions (Tables 3 and 4). A total of $5.8 \%$ of dentists reported untreated dental caries, and $14.8 \%$ reported fractured restorations; $4.8 \%$ reported having active periodontal disease, and only $70.8 \%$ reported not having any oral health problems. Extraordinarily, $0.3 \%$ reported toothache and 3.3\% reported having teeth that needed to be extracted, despite being a practicing dentist in the USA.

TABLE 2 Oral health behaviors

\begin{tabular}{|c|c|}
\hline Last comprehensive dental examination & $N=87$ \\
\hline$<6$ months ago & $169(43.7 \%)$ \\
\hline 6-12 months ago & $91(23.5 \%)$ \\
\hline $12-18$ months ago & $55(14.2 \%)$ \\
\hline 18 months- 3 years ago & $33(8.5 \%)$ \\
\hline $3-5$ years ago & $14(3.6 \%)$ \\
\hline $5-8$ years ago & $6(1.6 \%)$ \\
\hline$>8$ years ago & $19(4.9 \%)$ \\
\hline $\begin{array}{l}\text { Never had a comprehensive dental examination } \\
\text { that I can remember }\end{array}$ & 0 \\
\hline Last diagnostic bitewing radiographs & $N=390$ \\
\hline$<6$ months ago & $114(29.2 \%)$ \\
\hline 6-12 months ago & $147(37.7 \%)$ \\
\hline $12-18$ months ago & $66(16.9 \%)$ \\
\hline 18 months -3 years ago & $46(11.8 \%)$ \\
\hline $3-5$ years ago & $12(3.1 \%)$ \\
\hline 5-years ago & $3(.8 \%)$ \\
\hline$>8$ years ago & $2(.5 \%)$ \\
\hline $\begin{array}{l}\text { Never had bite wing radiographs that I can } \\
\text { remember }\end{array}$ & 0 \\
\hline How do you know your dentist & $N=388$ \\
\hline I do not regularly attend a particular dentist & $37(9.5 \%)$ \\
\hline $\begin{array}{l}\text { My co-worker (dentist) checks and manages my } \\
\text { oral health }\end{array}$ & $114(29.4 \%)$ \\
\hline $\begin{array}{l}\text { My co-worker (non-dentist) checks and manages } \\
\text { my oral health }\end{array}$ & $16(4.1 \%)$ \\
\hline $\begin{array}{l}\text { A friend (dentist) at another practice checks and } \\
\text { manages my oral health }\end{array}$ & $172(44.3 \%)$ \\
\hline $\begin{array}{l}\text { I have an independent dentist who manages my } \\
\text { oral health }\end{array}$ & $35(9 \%)$ \\
\hline Other & $14(3.6 \%)$ \\
\hline
\end{tabular}

In the current study, we asked dentists in Massachusetts to report their relationship to their dental provider. Remarkably, $4.1 \%$ of dentists reported that their non-dentist co-worker examined and managed their oral health. It is beyond the scope of this pilot study

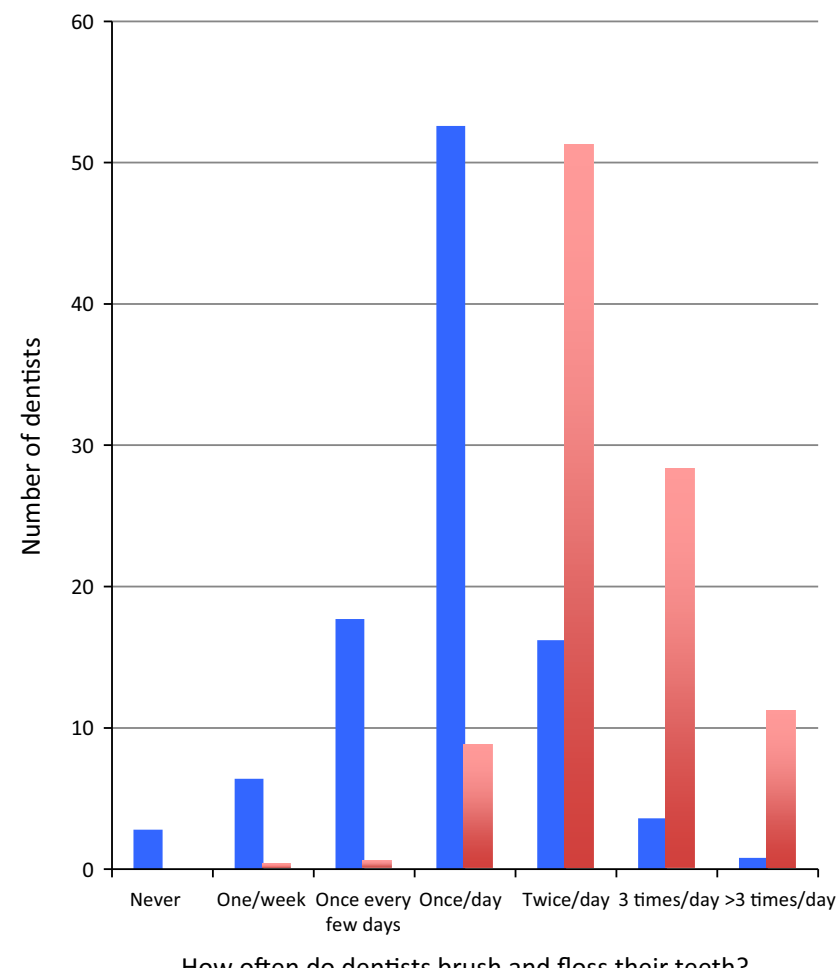

FIGURE 1 How often do dentists floss and brush their own teeth? . ( $\square$ ) How often do you floss your teeth?(\%); ( $\square$ ) How often do you brush your teeth?(\%)

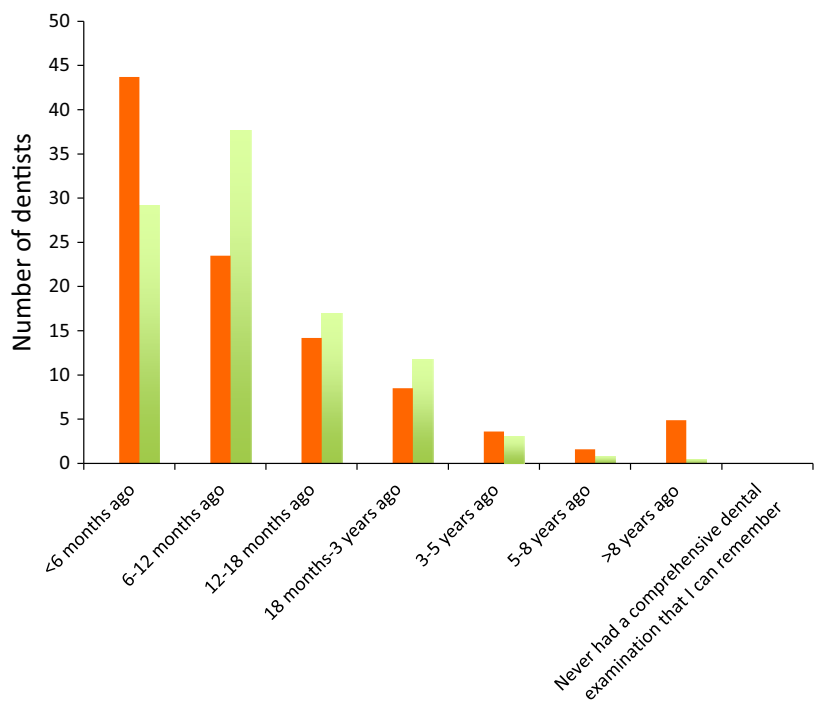

When did dentists last have a comprehensive dental examination and diagnostic bitewing radiographs?

FIGURE 2 Time since dentists' last comprehensive dental examination and bitewings . $(\square) \mathrm{N}=387$; ( $\square$ ) Last comprehensive dental examination; ( $)$ Last diagnostic bitewing radiographs 
TABLE 3 Oral health conditions

\begin{tabular}{|lc|}
\hline Oral health condition & $\mathbf{N}(\%)$ \\
\hline Untreated dental caries & $23(5.8 \%)$ \\
\hline Fractured restoration & $59(14.8 \%)$ \\
\hline Toothache & $1(0.3 \%)$ \\
\hline Tooth requiring extraction & $13(3.3 \%)$ \\
\hline Oral ulcers & 0 \\
\hline Periodontal disease & $19(4.8 \%)$ \\
\hline Cyst of the jaw bone & 0 \\
\hline Other oral health problems & $13(3.3 \%)$ \\
\hline No oral health problems & $283(70.8 \%)$ \\
\hline
\end{tabular}

TABLE 4 Oral hygiene practices

\begin{tabular}{|lc|}
\hline How often do you brush your teeth? & $\mathrm{N}=389(\%)$ \\
\hline Once/week & $1(0.3 \%)$ \\
\hline Once every few days & $2(0.5 \%)$ \\
\hline Once/day & $34(8.7 \%)$ \\
\hline Twice/day & $199(51.2 \%)$ \\
\hline 3 times/day & $110(28.3 \%)$ \\
\hline 3 times/day & $43(11.1 \%)$ \\
\hline How often do you floss your teeth? & $\mathrm{N}=390(\%)$ \\
\hline Never & $11(2.8 \%)$ \\
\hline Once/week & $25(6.4 \%)$ \\
\hline Once every few days & $69(17.7 \%)$ \\
\hline Once/day & $205(52.6 \%)$ \\
\hline Twice/day & $63(16.2 \%)$ \\
\hline 3 times/day & $14(3.6 \%)$ \\
\hline$>3$ times/day & $3(0.8 \%)$ \\
\hline
\end{tabular}

TABLE 5 Obstacles in accessing medical or dental care

\begin{tabular}{|lr|}
\hline Obstacles & N (\%) \\
\hline Cost & $31(7.8 \%)$ \\
\hline Time & $148(37 \%)$ \\
\hline $\begin{array}{l}\text { Geographic location (no physicians nearby) } \\
\text { Physician/dentist skill (physician/dentist } \\
\text { nearby cannot manage my medical/dental } \\
\text { concerns) }\end{array}$ & $7(1.5 \%)$ \\
\hline Other & $13(3.3 \%)$ \\
\hline
\end{tabular}

to evaluate the ethical dilemma of asking non-dentist health professionals, who you employ, to perform oral health services. Additionally, $9.5 \%$ reported that they do not regularly attend a dentist. The majority (44.3\%) reported that their dentist friend at another practice managed their oral health, and $29.4 \%$ reported that their dentist co-worker managed their oral health.

When describing the obstacles in trying to access medical and dental services (Table 5), 37\% of responders blamed a lack of time, and $7.8 \%$ reported that cost was prohibitive. It is interesting that some of the most common reasons for pursuing dentistry are balanced lifestyle, autonomy, and high income. ${ }^{15-17}$ However, dentists are not taking advantage of these benefits and seeking the medical/dental care they need. This pilot study has described the oral health and oral health practices of dentists in Massachusetts.

\section{5 | CONCLUSIONS}

The dental team is responsible for caring for the oral health of the community. As role models for oral health, it is important that the oral health of the dental team is stable. The current study showed that many dentists do not have stable oral health and might fail to follow the prevention guidelines that they recommend to their own patients. This could be perceived in a similar manner to an overweight athletic trainer, and there must be alignment in what dentists do for their own oral health and what they ask their patients to do.

\section{ORCID}

Romesh P. Nalliah (iD http://orcid.org/0000-0002-6287-0656

\section{REFERENCES}

1. Esmeili T, Ellison J, Walsh MM. Dentists' attitudes and practices related to diabetes in the dental setting. J Public Health Dent. 2010;70:108-114.

2. Nalliah RP, Budd A, Allareddy V. Pilot survey of the health of Massachusetts dentists. J Investig Clin Dent. 2017; https://doi. org/10.1111/jicd.12263

3. America Dental Association. Research Brief. Available at www. ada.org/ /media/ADA/Science\%20and\%20Research/HPI/Files/ HPIBrief_0616_1.pdf. Accessed 22 June 2017.

4. America Dental Association. Membership. Available at www.ada.org/ en/member-center/join-or-renew-ada-membership. Accessed 14 June 2017.

5. America Dental Association. Income and Gross Billings. Accessed 10 Jun 2017 and available at www.ada.org/1444.aspx

6. Guay AH, Wall TP, Petersen BC, Lazar VF. Evolving trends in size and structure of group dental practices in the United States. J Dent Educ. 2012;76:1036-1044.

7. America Dental Association. Available at https://money.usnews.com/ careers/best-jobs/dentist/salary. Accessed 12 June 2017.

8. Survey Gizmo. 3 Ways to Improve Your Survey Response Rates. Available at www.surveygizmo.com/survey-blog/survey-responserates/. Accessed 17 Nov 2016.

9. American Dental Association. Brushing your teeth. Available at http://www.mouthhealthy.org/en/az-topics/b/brushing-your-teeth. Accessed 29 June 2017.

10. America Dental Association. News Releases. Available at www. ada.org/en/press-room/news-releases/2016-archive/August/ statement-from-the-american-dental-association-about-interdental-cleaners. Accessed 29 June 2017.

11. Colgate. How Often Should You Go To The Dentist? Available at www. colgate.com/en/us/oc/oral-health/basics/dental-visits/article/howoften-should-you-go-to-the-dentist. Accessed 10 July 2017.

12. America Dental Association. News Releases. Available at www. ada.org/en/press-room/news-releases/2013-archive/June/ 
american-dental-association-statement-on-regular-dental-visits. Accessed 2 June 2017.

13. Delta Dental. Available at https://nedelta.com/oral-health-andwellness/articles/dental-visits-for-patients-with-dentures. Accessed 17 July 2017.

14. America Dental Association. Dental Radiographic Examinations: Recommendations for Patient Selection and Limiting Radiation Exposure. Available at www.ada.org/ /media/ADA/Publications/ ADA\%20News/Files/Dental_Radiographic_Examinations_2012.pd$\mathrm{f}$ ?la=en. Accessed 29 May 2017.

15. American Dental Association. Be a Dentist. Available at www.ada.org/ en/education-careers/careers-in-dentistry/be-a-dentist. Accessed 16 September 2015.
16. Hallissey J, Hannigan A, Ray N. Reasons for choosing dentistry as a career-a survey of dental students attending a dental school in Ireland during 1998-1999. Eur J Dent Educ. 2000;4:77-81.

17. US News. Dentist Salary. Available at http://money.usnews.com/careers/best-jobs/dentist/salary. Accessed 22 July 2017.

How to cite this article: Nalliah RP, Allareddy V. Practicing what we preach: A pilot study on oral health practices of dentists in Massachusetts. J Invest Clin Dent. 2018;9:e12322. https://doi. org/10.1111/jicd.12322 